\title{
Central Auditory Processing Disorder in Children
}

\author{
Akbar Darouie ${ }^{1}$, Farzaneh Zamiri Abdollahi ${ }^{2 *}$, Mamak Joulaie ${ }^{3}$ and Tayebeh Ahmadi ${ }^{4}$ \\ ${ }^{1} \mathrm{PhD}$ of speech language pathology, University of Social Welfare and Rehabilitation Sciences, Iran \\ ${ }^{2} \mathrm{PhD}$ of audiology of Audiology, AVA Rehabilitation Center, Iran \\ ${ }^{3}$ MSc of speech language pathology, AVA Rehabilitation Center, Iran \\ ${ }^{4} \mathrm{PhD}$ student of audiology, AVA Rehabilitation Center, Iran
}

Submission: April 14, 2017; Published: April 18, 2017

*Corresponding author: Farzaneh Zamiri Abdollahi, AVA Rehabilitation Center, Enghelab Street, Hadadi Blvd, Derakhti street, Karaj, Alborz, Iran, Tel: +982633555682; Email: audiology_zamiri@yahoo.com

\begin{abstract}
(Central) auditory processing disorder (C)APD refers to the auditory information processing difficulties in the central nervous system. (C)APD may coexist with, but is not the result of, dysfunction in other modalities. The most important comorbidities are Attention Deficit Hyperactivity Disorder, autism, Specific language impairment and dyslexia. There is high prevalence of (C)APD among children with recurrent otitis media. Early referral to audiologist for diagnosis is vital to prevent any academic failure.
\end{abstract}

Keywords: Central auditory processing disorder; Spatial hearing; Otitis media; Autism; Dyslexia; Attention Deficit; Specific Language Impairment

Abbreviations: (C)APD: (Central) Auditory Processing Disorder; SOM: Secretory Otitis Media; ADHD: Attention Deficit Hyperactivity Disorder; SLI: Specific Language Impairment; AS: Asperger's Syndrome; SRTs: Speech Reception Thresholds

\section{Introduction}

(Central) auditory processing disorder (C)APD refers to the auditory information processing difficulties in the central nervous system. It is indicated by poor performance in one or more of the auditory skills: sound localization and lateralization; auditory discrimination; auditory pattern recognition; temporal aspects of audition, including temporal integration, temporal discrimination (e.g., temporal gap detection), temporal ordering, and temporal masking; auditory performance in competing acoustic signals (including dichotic listening); and auditory performance with degraded acoustic signals [1].

Cognitive disorders and language problems may also cause low scores in auditory tasks but it is important to remember that (C)APD is not due to higher order language, cognitive, or related factors [2]. (C)APD may coexist with, but is not the result of, dysfunction in other modalities [3]. (C)APD can also lead to or be associated with difficulties in learning (e.g., spelling, reading), speech, language, attention, social, and related functions [3]. Diagnosis of (C)APD needs comprehensive assessment of each individual suspected of having (C)APD [4].

\section{(C)APD \& Otitis Media}

About two-thirds of children have at least one episode of secretory otitis media ( $\mathrm{SOM}$ ) between 1 and 5 years of age.
If medical intervention is not performed early, otitis media can cause hearing loss. As a result, the child experiences mild or moderate conductive hearing loss that usually fluctuates. In otitis media, there are periods of normal hearing, its fluctuating character leads to in consistent sound stimulation of the auditory central nervous system and distorts sound perception. Speech discrimination, especially in noisy environments, and phonological awareness skills can also be affected and consequently negatively affect school performance [5]. Horizontal localization needs comparing auditory stimuli reaching two ears (interaural time difference and interaural loudness difference) [6]. Asymmetric hearing loss impair spatial hearing. Otitis media with effusion usually cause more hearing loss in one ear than the other ear this asymmetric hearing loss cause binaural hearing difficulties [7].

\section{(C)APD \& Attention Deficit Hyperactivity Disorder (ADHD)}

(C)APD and ADHD have similar symptoms but they seem to be distinct entities [8]. A number of similar symptoms include attention and listening problems, maladaptive behavior, distractibility, instruction-following difficulty, and increased time required to complete tasks [9]. (C)APD and ADHD may be 
independent but comorbid conditions [10]. (C)APD is diagnosed on the basis of performance deficits on a battery of behavioral tests and, in some cases, by electrophysiologic indicators of central auditory function. DSM-IV is used for diagnosing ADHD. Diagnosis of ADHD Subtypes ((C)APD is an input deficit and ADHD is an output/behavioral deficit [11].

\section{(C)APD \& Dyslexia}

Prevalence of (C)APD in children diagnosed with Learning Disabilities in general is estimated to be as high as $30-50 \%$. Learning Disabilities according to the DSM-IV are diagnosed when a subject's achievement on individually administered standardized tests in reading, mathematics or written expression is substantially below that expected for age, school level and IQ. One specific learning disability is dyslexia (reading disability) [12]. Individuals with dyslexia have significant and continuous reading difficulties in spite of adequate general intelligence and education. They comprise about $10 \%$ of school children. Most subjects with dyslexia suffer from poor phonological processing, poor verbal working memory and poor performance in simple psychoacoustic tasks [13]. (C)APD deficits in subjects with dyslexia must be treated, as the presence of this disorder may compromise a child's ability to successfully process auditory information in less than ideal situations (e.g. noisy environments) and may interfere with the learning process [13]

\section{(C)APD \& Specific Language Impairment (SLI)}

CAPD may coexist in children with speech-language impairments. Speech comprehension disorders are typical for all patients with (C)APD and SLI. It was concluded that the temporal characteristics of auditory stimuli are critical for children with SLI. When stimuli are either brief or rapid, children have difficulty in discriminating them, although they have no difficulty in differentiating the same stimuli when they are lengthened or presented at a slower rate. This rapid processing deficit has a severe impact on language development, which is crucially dependent on the ability to recognize very brief rapid stimuli. At the heart of SLI there is impairment of auditory perception [14].

In children with SLI following disorders can be seen: deficit in speech sounds decoding, integration deficit for the demands of the stimuli temporal sequence, the shortterm(working)memory disorder, all lead to general reduction of the communication perceived and to association problems [15]. Tests of the integration deficit, also show difficulties in the linked association area in children with SLI. In speech perception, temporal processing represents is important for recognizing the phonemes. Temporal characteristics of auditory stimuli are critical for children with SLI. In respect of these findings, the developmental speech-language disorders are considered as the central auditory processing disorders [15].

\section{(C)APD \& Autism Spectrum Disorder (ASD)}

ASD is a spectrum of neuro developmental disorders characterized by qualitative impairments in social interaction and communication, engagement in repetitive behaviors and reliance on routine. Standard diagnostic manuals such as the DSM-IV and ICD-10 have divided ASDs into different subtypes of which Autistic Disorder (or autism) and Asperger's syndrome (AS) are the most commonly studied [16,17]. Symptoms of Autism and AS are similar, however individuals with AS typically function at the higher end of the spectrum [18]. The diagnosis of AS is only given in the absence of significant language and/or cognitive delay [19]. Past research has found substantial auditory processing difficulties in ASD. Differences are diverse and have been found for both speech and non-speech stimuli. Studies range from physical properties of acoustic stimuli, (i.e. pitch and loudness) to perception of more complex auditory information such as prosody [19]. Individuals on the autistic spectrum are often hypersensitive to loud sounds. Hypersensitivity to noise can cause great distress and anxiety to individuals on the spectrum [20].

The ability to extract meaning from a target speech in presence of a background of competing sources and/or environmental noise is known as auditory stream segregation. This process is dependent on discrimination of acoustic cues specific to the target speaker (i.e. pitch, timing, location) from extraneous auditory information and is modulated by top-down processes such as attention, language and working memory [21]. Speech extraction from simultaneous auditory streams is facilitated by the ability to take advantage of spectral and temporal dips in competing noise. Signal-to-noise ratios increase substantially in the presence of dips [22]. ASD have often reported difficulty understanding speech in noisy environments [23]. Studies show that adults with autism obtained significantly higher speech reception thresholds (SRTs) for speech noise containing temporal dips $[19,24]$.

\section{(C)APD diagnosis}

(C)APD is an auditory deficit; therefore, it continues to be the position of ASHA that the audiologist is the professional who diagnoses (C)APD. Consistent with the ASHA Scope of Practice in Speech-Language Pathology, speech-language pathologists (and other professionals) work with the audiologist in the overall screening and assessment process, differential diagnosis, and development and implementation of intervention plans where there is evidence of speech-language and/or cognitivecommunicative disorders [25].

\section{(C) APD intervention}

Intervention for (C)APD typically requires an interdisciplinary approach involving the audiologist, speechlanguage pathologist, and other professionals, and should be implemented as a team work by the audiologist and speechlanguage pathologist (and possibly others) as soon as possible following the diagnosis to make use of the plasticity of the CNS. Treatment and management goals are deficit driven and are determined on the basis of diagnostic test findings, the 
individual's case history, and related speech-language and psychoeducational assessment data. Treatment and management of (C)APD should incorporate both bottom-up (e.g., acoustic signal enhancement, auditory training) and top-down (i.e., cognitive, metacognitive, and language strategies) approaches delivered consistent with neuroscience principles [25].

\section{Conclusion}

(C)APD is one of the auditory system disorders that need special attention in field of audiology, speech language pathology and otolaryngology. It is important to refer children suspected to (C)APD to audiologists for early diagnosis and management. This may prevent school failure.

\section{References}

1. Association ASLH (2005) (Central) auditory processing disorders.

2. Ludwig AA, Fuchs M, Kruse E, Uhlig B, Kotz SA, et al. (2014) Auditory processing disorders with and without central auditory discrimination deficits. J Assoc Res Otolaryngol 15(3): 441-464.

3. Northern JL, MP Downs (2002) Hearing in children. Lippincott Williams \& Wilkins, USA.

4. Musiek FE, GD Chermak (2013) Handbook of Central Auditory Processing Disorder, Volume I: Auditory Neuroscience and Diagnosis. Plural Publishing, USA.

5. Borges LR, Paschoal JR, Colella-Santos MF (2013) (Central) Auditory Processing: the impact of otitis media. Clinics 68(7): 954-959.

6. G Christopher Stecker, Frederick Gallun (2012) Binaural hearing sound localization, and spatial hearing. Translational perspectives in auditory neuroscience: Normal aspects of hearing 383-434.

7. Keating P, King AJ (2013) Developmental plasticity of spatial hearing following asymmetric hearing loss: context-dependent cue integration and its clinical implications. Front Syst Neurosci 7: 123.

8. Ptok M, Buller N, Schwemmle C, Bergmann C, Lüerssen K (2006) Auditory processing disorder versus attention deficit/hyperactivity disorder. A dysfunction complex or different entities? HNO 54(5): 405$408,410-414$

9. Chermak GD, Somers EK, Seikel JA (1998) Behavioral signs of central auditory processing disorder and attention deficit hyperactivity disorder. J Am Acad Audiol 9(1): 78-84.

10. Tavegia BD (2009) Sensory deficits and their relationship to pervasive developmental disorders and attention deficit/hyperactivity disorder in an urban preschool population. Azusa Pacific University.
11. Chermak GD, Hall JW, Musiek FE (1999) Differential diagnosis and management of central auditory processing disorder and attention deficit hyperactivity disorder. J Am Acad Audiol 10(6): 289-303.

12. Iliadou V, Bamiou DE, Kaprinis S, Kandylis D, Kaprinis G (2009) Auditory Processing Disorders in children suspected of Learning Disabilities-A need for screening? International Journal of Pediatric Otorhinolaryngology 73(7): 1029-1034.

13. Banai K, M Ahissar (2006) Auditory processing deficits in dyslexia: task or stimulus related? Cerebral Cortex 16(12): 1718-1728.

14. Bishop D (2000) Uncommon Understanding: Development and Disorders of Language Comprehension in Children. Adolescence 35(138): 417.

15. Dlouha O, Novak A, Vokral J (2007) Central auditory processing disorder (CAPD) in children with specific language impairment (SLI): Central auditory tests. Int J Pediatr Otorhinolaryngol 71(6): 903-907.

16. King BH, Navot N, Bernier R, Webb SJ (2014) Update on diagnostic classification in autism. Curr Opin Psychiatry 27(2): 105.

17. Lord C, RM Jones (2012) Annual Research Review: Re-thinking the classification of autism spectrum disorders. J Child Psychol Psychiatry 53(5): 490-509.

18. Baron-Cohen S, Wheelwright S, Skinner R, Martin J, Clubley E (2001) The autism-spectrum quotient (AQ): Evidence from asperger syndrome/high-functioning autism, malesand females, scientists and mathematicians. J Autism Dev Disord 31(1): 5-17.

19. O'Connor K (2012) Auditory processing in autism spectrum disorder: a review. Neurosci Biobehav Rev 36(2): 836-854.

20. Morris R (2009) Managing sound sensitivity in autism spectrum disorder: new technologies for customized intervention. Massachusetts Institute of Technology.

21. Anderson S, N Kraus (2010) Sensory-cognitive interaction in the neural encoding of speech in noise: a review. J Am Acad Audiol 21(9): 575-585.

22. Oxenham AJ (2008) Pitch perception and auditory stream segregation: implications for hearing loss and cochlear implants. Trends Amplif 12(4): 316-331.

23. Bellis TJ (2004) Understanding auditory processing disorders in children. ASHA-American Speech-Language-Hearing Association.

24. Alcántara JI, Weisblatt EJ, Moore BC, Bolton PF (2004) Speech-in-noise perception in high-functioning individuals with autism or Asperger's syndrome. J Child Psychol Psychiatry 45(6): 1107-1114.

25. Association ASLH (Central) Auditory Processing Disorders-The Role of the Audiologist. ASHA.

\section{Your next submission with Juniper Publishers will reach you the below assets}

- Quality Editorial service

- Swift Peer Review

- Reprints availability

- E-prints Service

- Manuscript Podcast for convenient understanding

- Global attainment for your research

- Manuscript accessibility in different formats

( Pdf, E-pub, Full Text, Audio)

- Unceasing customer service

Track the below URL for one-step submission https://juniperpublishers.com/online-submission.php 